\title{
Classification of two-phase flow patterns using multifractal analysis of pressure oscillations
}

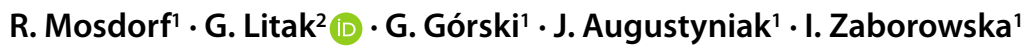 \\ Received: 12 March 2019 / Accepted: 22 September 2021 / Published online: 27 October 2021 \\ (c) The Author(s) 2021
}

\begin{abstract}
The two-phase flow patterns (air-water) in horizontal square minichannel $(3 \times 3 \mathrm{~mm})$ has been analysed. The multifractal analysis of pressure drop fluctuations was used for qualitative assessment of two-phase flow patterns. The results of the complexity analysis using the multifractal spectral width $(\Delta h)$ are presented. The proposed method allows us to identify the following two-phase flow patterns: micro-bubbles flow, micro- and minibubbles flow, micro- and mini-bubbles with confined bubbles flow, slug flow, stratified flow. The obtained results confirm that this type of analysis can be considered as an alternative way of identification of two-phase flow patterns in the minichannel. The work also focuses on the discussion of the occurrence and identification of bubbles churns in slugs and churns.
\end{abstract}

\section{Klassifizierung des Zweiphasenströmungsmusters unter Verwendung der multifraktalen Analyse der Druckabfallschwankungen}

\section{Zusammenfassung}

Die Zweiphasenströmungsmuster (Luft-Wasser) in einem horizontalen quadratischen Minikanal $(3 \times 3 \mathrm{~mm})$ wurden analysiert. Die multifraktale Analyse der Druckabfallschwankungen wurde zur qualitativen Bewertung der Zweiphasenströmungsmuster verwendet. Die Ergebnisse der Komplexitätsanalyse unter Verwendung der multifraktalen spektralen Breite $(\Delta h)$ werden vorgestellt. Mit der vorgeschlagenen Methode lassen sich folgende Zweiphasenströmungsmuster identifizieren: Mikroblasenströmung, Mikro- und Miniblasenströmung, Mikro- und Miniblasenströmung mit eingeschlossenen Blasen, Schneckenströmung, geschichtete Strömung. Die erzielten Ergebnisse bestätigen, dass diese Art der Analyse als alternativer Weg zur Identifizierung von Zweiphasen-Strömungsmustern in einem Minikanal betrachtet werden kann. Die Arbeit konzentriert sich auch auf die Erörterung des Auftretens und der Identifizierung von Blasenwolke, die in dem Luftblasen Sturm aufgewirbelt werden.

\section{Introduction}

Two-phase flow is observed in technical systems in where liquid and gas appears. Recent studies were conducted to explain patterns formations in two-phase flow in pipes and minichannels [1-4]. The chronological visualization of twophase flow patterns and the identification of several distinc-

G. Litak

g.litak@pollub.pl

1 Faculty of Mechanical Engineering, Bialystok University of Technology, Wiejska 45C, 15-351 Bialystok, Poland

2 Faculty of Mechanical Engineering, Lublin University of Technology, Nadbystrzycka 36, 20-618 Lublin, Poland tive flow patterns were carried out by Triplett et al. [5] and Serizawa et al. [6]. The correlation dimensions, Hurst and Lyapunov exponents, Kolmogorov entropy were used by Wang et al. [7] and Jin et al. [8]. Very recently, two-phase flows were studied by means of recurrence statistics applied to laser-photo-transistor light transitivity time series [9-11]. These investigations allowed to identify the transitions from bubbles to slugs and to churn. The instabilities of the considering patterns can be also identified. The complex multiscale character of flows was claimed by Fan et al. [12, 13] who also used the data of light transmission through a minichannel. In this context, the multiscale morphological analysis was proposed by Lian et al. [14]. The authors of ref [14]. used electric conductance signals. Finally, Faszczewski et al. [15] and Litak [16] determined the bor- 
Fig. 1 Scheme of experimental stand: 1 . minichannel nade with a transparent pipe, 2. pressure sensors (MPX12DP), 3. laser-phototransistor sensor, 4. Casio EX-FX1 camera, 5. lighting, 6. pumps (air or water), 7. flow metres, 8 . minibubbles generator, 9. air tank, 10. automatic valve to maintain a constant pressure in the tank 9,11 . data acquisition station (DT9800), 12. computer, 13. water tank, 14. air tank

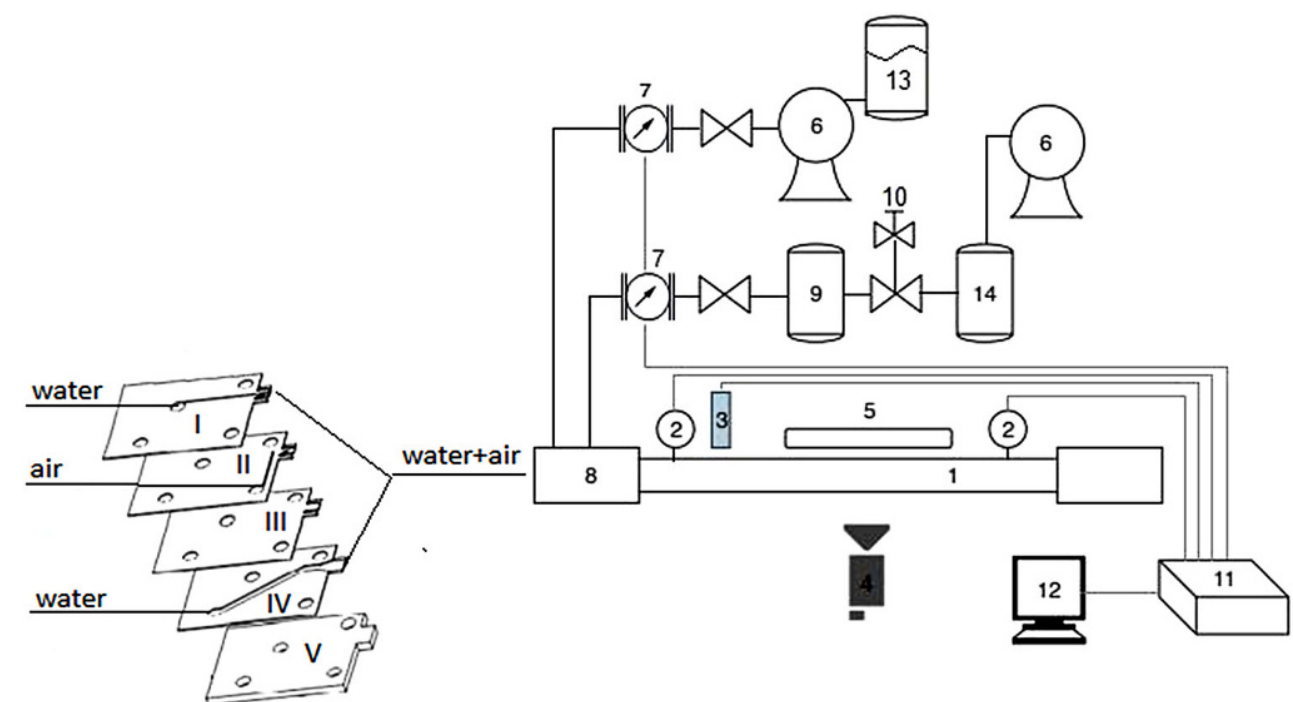

ders between the two-phase flows patterns in terms of complexity factors defined recurrence qualificators. Górski et al. [17] proposed multifractals to study intermediate states between different two-phase flows. Continuing this direction of research, the systematic quantification of the borders between bubble patterns leads us to propose, in the present paper, a new schema of classification for the flow patterns by multifractals.

\section{Experimental setup and pressure oscillations}

Flow patterns (water-air conditions $21^{\circ} \mathrm{C}$ ) in a horizontal square channel with dimension a $3 \mathrm{~mm}$ by $3 \mathrm{~mm}$ were investigated. The experimental setup is described in detail in the work [18] and also schematically shown in Fig. 1. Due to the size of the minichannel, obtaining a bubble flow in its interior is difficult, therefore a special mini bubble generator was used (8-Fig. 1). The bubble generator was made of 8 sheets of stainless steel, and each with a thickness of $0.5 \mathrm{~mm}$. In Fig. 1 (at the left hand side) the schema of 5 sheets were shown. Last the three upper sheets are similar to sheets II, IV, V. In the sheets the slots have been cut out through with holes which the gas phase and water into the interior of the minichannel are supplied. The locations of slots are shown in Fig. 1. The generator produced bubbles into the minichannel. The air was supplied through a nozzle with a dimension of $0.25 \times 0.5 \mathrm{~mm}$. The two outer channels were used to provide additional water to the minichannel. To maintain a constant overpressure in the supply tank, a proportional pressure regulator (Metal Work Regtronic with an accuracy of $1 \mathrm{kPa}$ ) was used (10-Fig. 1) - the overpressure was $50 \mathrm{kPa}$. To record flow patterns, the Ca- sio EX-F1 digital camera at $1200 \mathrm{fps}(336 \times 96$ pixels $)$ was used (4-Fig. 1).

The differential pressure between the inlet and outlet of the minichannel was measured using the silicone pressure sensor MPX12DP to get the pressure drop of the mixture. A laser-phototransistor sensor was used to measure the amount of gas phase and liquid inside the mini-channel (3-Fig. 1). The sensor was composed of: a laser module that generated a laser beam with a diameter of $3 \mathrm{~mm}$, a lens and a silicon sensor placed at the focus of the lens. All sensors were connected to the data acquisition station DT 9804 (11-Fig. 1), which collected data with a sampling frequency of $1 \mathrm{kHz}$.

Fig. 2 shows the example of time series of signal recorded from the pressure sensors for various air volume flow rates, $q_{a}$. The values presented in Fig. 2 are calculated as differences between the pressure measurement at the beginning and end of the minichannel. The pressure changes are presented in the some scale because the increase of air volume flow rate cause the increase of pressure fluctuations amplitude. By increasing the air volume flow rate we observe evolution in the time series including small regular like oscillations (Fig. 2a,b for $q_{a}=0.001$ and $0.005 \mathrm{l} / \mathrm{min}$ ) which are later suppressed (Fig. 2c,d for $q_{a}=0.008$ and $0.0131 / \mathrm{min})$.

Pressure drop fluctuations describe the two-phase flow conditions in the whole minichannel. The pressure drop fluctuations contain much more information about flow conditions in comparison with data recorded by laser-phototransistor sensor. In the pressure signal we can observe pressure changes in time appearing in different time scale.

Further increase of $q_{a}$ restores oscillations (Fig. 2e-g for $q_{a}=0.025,0.0033$ and $0.0421 / \mathrm{min}$, respectively). However, with a more detailed examination it clear that their form is less periodic compared to the low $q_{a}$ limit (cases in 

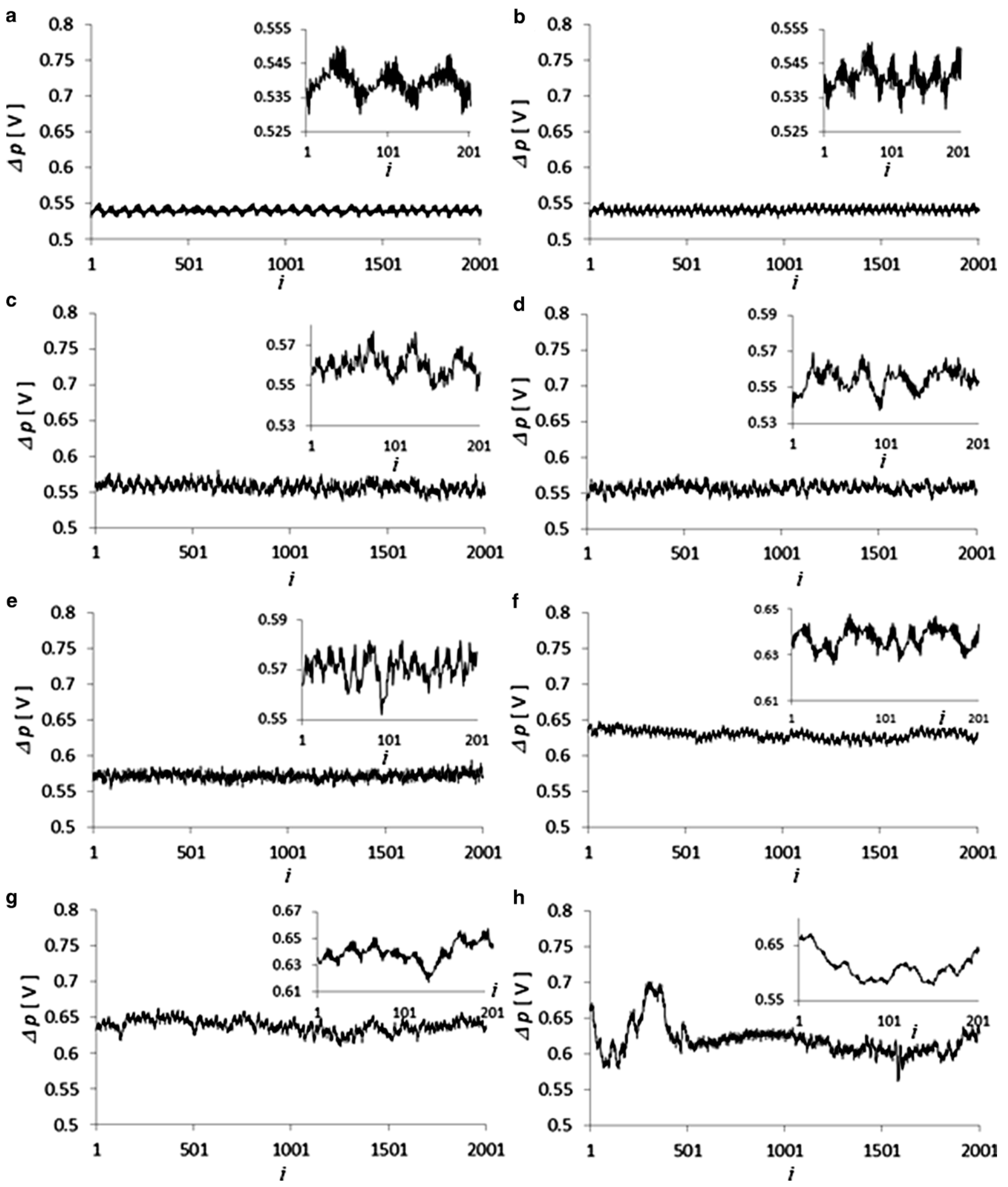

Fig. 2 Examples of time series obtained from pressure sensor for $q_{w}=0.0571 / \mathrm{min}$, (a) $q_{a}=0.0011 / \mathrm{min}$, (b) $q_{a}=0.0051 / \mathrm{min},(\mathbf{c}) q_{a}=0.0191 / \mathrm{min}$, (d) $q_{a}=0.0251 / \mathrm{min}$, (e) $q_{a}=0.0421 / \mathrm{min}$, (f) $q_{a}=0.1001 / \mathrm{min}$, (g) $q_{a}=0.21 / \mathrm{min}$, (h) $q_{a}=0.31 / \mathrm{min}$. Pressure was measured in the voltage [V] due to sensors used in the experiment. The pressure drop was proportional to corresponding voltage difference 


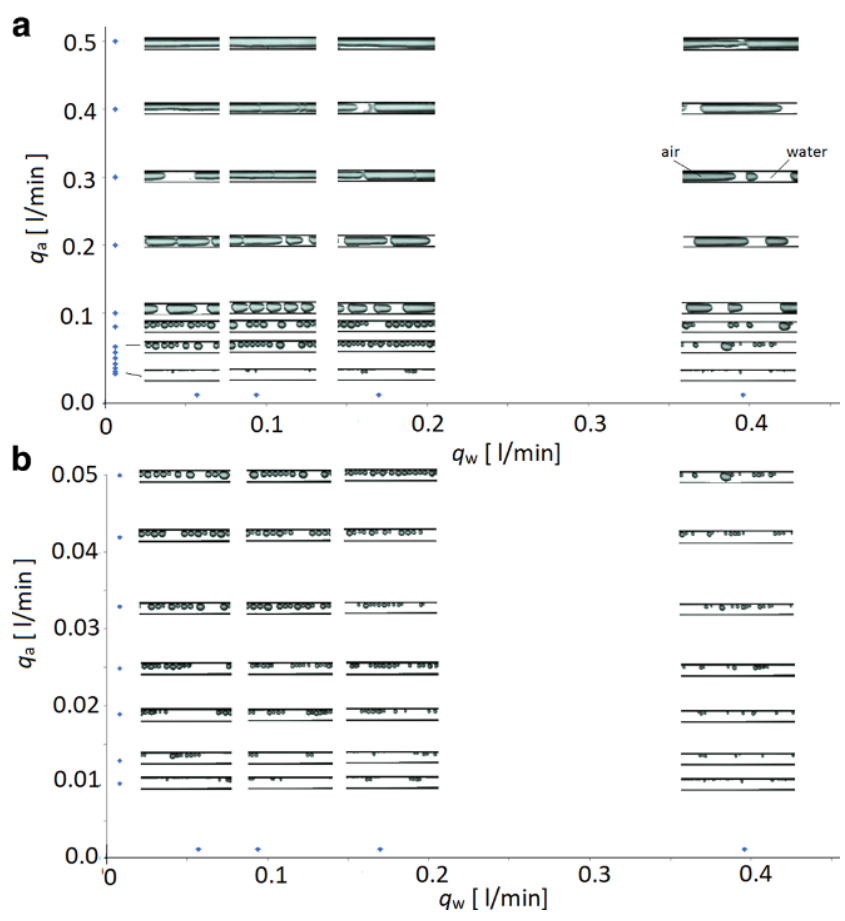

Fig. 3 An example of video frames recorded for different air (presented along vertical direction) and water flow (presented in horizontal direction) rates. Note that the first set of pictures on the left hand side is related to the pressure measurements shown in Fig. 2. Simultaneously, the estimated average velocity of the air flow and water flow are marked by the additional vertical axis on the right and bottom sides, respectively $\left(v_{w}\right.$ is the estimated flow velocity to the corresponding water flow rate $q_{w}$ )

Fig. 2a,b). It is also worth noting that up to this point (increase of $q_{a}$ ) the average level of pressure was very close in all considered cases. A larger value of $q_{a}$ causes a pressure difference leading to marked increase of this level (Fig. $2 \mathrm{~h}$ for $q_{a}=0.21 / \mathrm{min}$ ). Simultaneously the small oscillations are still present. Finally, the limit of large $q_{a}\left(q_{a}=0.4\right.$ and $0.5 \mathrm{l} / \mathrm{min}$ ) provides strong irregular pressure oscillations (see Fig. 2i,j). Comparing these last two figures it can be concluded that the amplitude of these oscillations has an increasing trend.

In Fig. 3 video frames obtained for various air and water flow rates are presented. The following flow patterns have been observed: flow of micro-bubbles, flow of micro and mini-bubbles, flow of micro- and mini-bubbles with confined bubbles, slug flow, stratified flow. Here, one can see more clearly physical phenomenon in the channel. Examining, their vertical evolutions (for all $q_{w}$ ) one can notice their qualitative similarity. For small $q_{a}$ small, mostly individual bubbles can be observed which together with the increase of $q_{a}$ grow in size and merge to form the bubbles of the maximum cross-section-short slugs. Finally, the short slugs merge to form longer and longer slugs. At the stages of small bubbles and short slugs, there are tendencies to form the optimal size of the bubbles and slugs and the space be- tween them leading to more regular oscillatory flow. These effects would have consequences in the pressure measurements (Fig. 2). Additionally, we observe the considerable quantitative differences in the change from $q_{w}$. Firstly, in the limit of larger $q_{w}$ regular phases seem to play a minor role compared to smaller $q_{w}$. Secondly, in a larger $q_{w}$ merging is less efficient.

\section{Multifractal analysis}

Knowledge regarding the behavior of the system at any time is the key to understanding its nature. Many phenomena, as for example turbulence or electric discharges, show multifractality [19]. For this reason, you cannot describe them in a fairly clear way. In order to characterize the complex features of many non-linear dynamic systems, multifractals are used.

Multifractal analysis is used in many contexts. The first works in which this method was used were studies of complex biological systems. Subsequent work focused on the characteristics of engineering systems, such as the analysis of earthquake distribution, signal processing or study instabilities in combustion engine [20-24]. It is also used in the medical field, eg pathology diagnostics or health monitoring.

In addition, analysis of multifractal is applied within the two-phase flows, eg. in order to characterize the structure of the inclined flow of oil and water [25] or to create a simulation of turbulent two-phase flow [26].

The multifractal analysis focuses mainly on the analysis of the spectrum of local exponential growth and multifractal spectrum. To find the local spectrum for each time series of pressure oscillations (expressed in volts) $u(i)=\Delta p(i)$, where $i$ represents the sampling index (Fig. 2), we should study their evolution in a short time along each of the measurement points $i$ and in the time series $u(i+\delta i)$. The next step is to search in the vicinity of each sampled voltage $i$ characteristic of the local exponent $h_{i}$ (usually non-intriguing), which estimates the appropriate difference:

$|u(i)-u(i+\delta i)| \leq a_{h} \delta i^{h}$.

In this formula, $a_{h}$ is a coefficient associated with the local exponent $h_{i}$.

Consequently, the multifractal voltage analysis $u$ refers to the spectrum of singularity $D(h)$ of all $h_{i}$ exponents along the tested time series $u(i)$, by supplying a special quantitative description of the system behavior [27-29]. In fact, $h_{i}$ describes the Hölder exponent, and the probability of its distribution $D(h)$ responds to the Hausdorff dimension of the dynamic system. The results of our calculations 
Fig. 4 The evolution of the critical exponents spectrum $h$ for fixed $q_{w}=0.0571 / \mathrm{min}$ and different air flows rates:
(a) $q_{a}=0.0011 / \mathrm{min}$,
(b) $q_{a}=0.005 \mathrm{l} / \mathrm{min}$,
(c) $q_{a}=0.0081 / \mathrm{min}$,
(d) $q_{a}=0.0131 / \mathrm{min}$,
(e) $q_{a}=0.0251 / \mathrm{min}$,
(f) $q_{a}=0.0331 / \mathrm{min}$
(g) $q_{a}=0.0421 / \mathrm{min}$,
(h) $q_{a}=0.21 / \mathrm{min}$,
(i) $q_{a}=0.41 / \mathrm{min}$,
(j) $q_{a}=0.5 \mathrm{l} / \mathrm{min}$
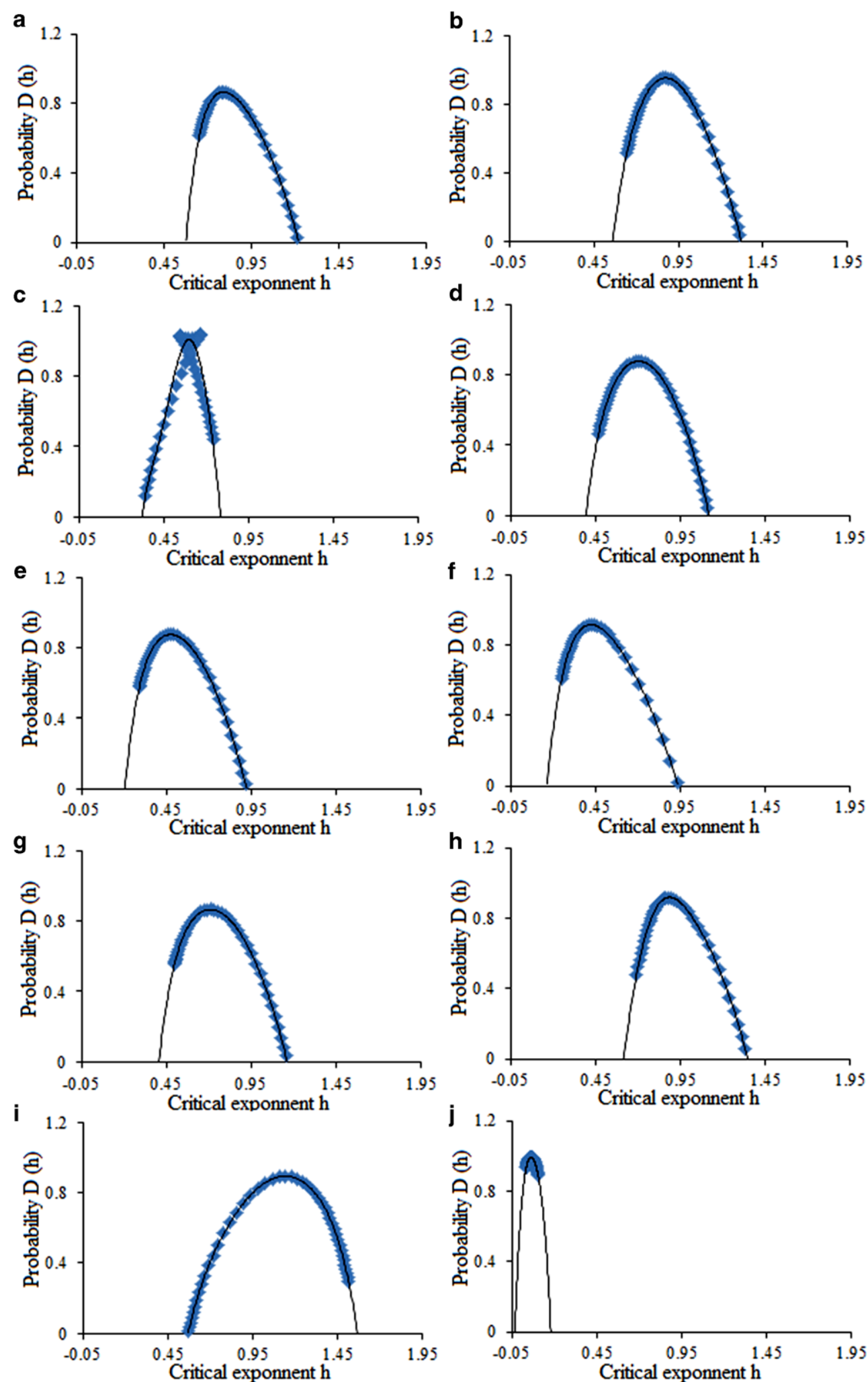


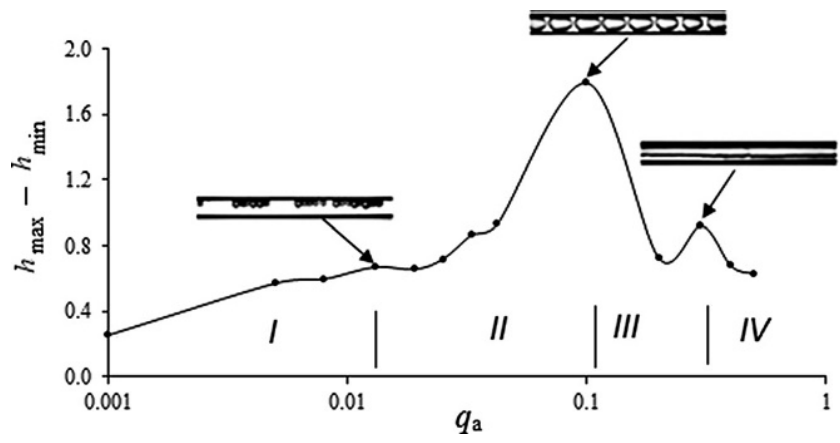

Fig. 5 Variation of $h_{\max }-h_{\min }$ versus $q_{a}$ (for fixed $q_{w}=0.0941 / \mathrm{min}$ ). Location of maxima of $\Delta h$ identify the $q_{a}$ value for which the flow pattern is changing. Note the sample camera snap shots added over the dependence curve to illustrate the corresponding flow patterns

are presented in Fig. 4. The spectral width $D(h)$ has been calculated according to the formula:

$\Delta h=h_{\max }-h_{\min }$,

where $h_{\min }$ and $h_{\max }$ are determined by values of nodal $D(h)=0$. The $\Delta h$ specifies the measure of the complexity of the system response, while the $h_{0}$ refers to the maximal value of the $D(h)$ and estimates the average exponent, pointing out the randomness of the pressure fluctuation.

Generally, the $h_{0}$ exponent is used to determine the nature of the data and the strength of the dependency between the analyzed data. Therefore, for $h_{0}=0.5$ the relationship between the data does not exist and we are dealing with a stochastic Brownian motion, for which the next steps are independent of each other. Where $h_{0}>0.5$ the process is called persistent, where there are long-term dependencies ( $u(i)$ of neighbors $i$ is positively correlated), while $h_{0}<0.5$ the process is anti-persistent $(u(i)$ for neighbors $i$ is negatively correlated) [17]. Namely, describing $\Delta h$ and $h_{0}$ can be stated that the wider the range of possible fractal exponents, the richer the dynamic structure of the system is. Taking into account the fact that the greater $h_{0}$ means more correlated fluctuations (data are less random). An example of the results of the complexity analysis $\Delta h$ is shown in Fig. 4.

Multiracial spectrum was reconstructed using the WTMM method. It has been used the program presented in the paper [28]. The curves presented in the charts in Fig. 4 are the approximation polynomial of degree between 4 and 6 . The polynomial degree was individually calculated for charts in order to obtain the better fitting of the approximation curve. The approximation curves were used for calculation of $h_{\min }$ and $h_{\max }$.

In Fig. 5 it has been presented the example of changes of the difference $h_{\min }$ and $h_{\max }$ versus air volume flow rate with constant water volume flow rate $q_{w}=0.0941 / \mathrm{min}$. The local maximums of function were marked by arrows and also the

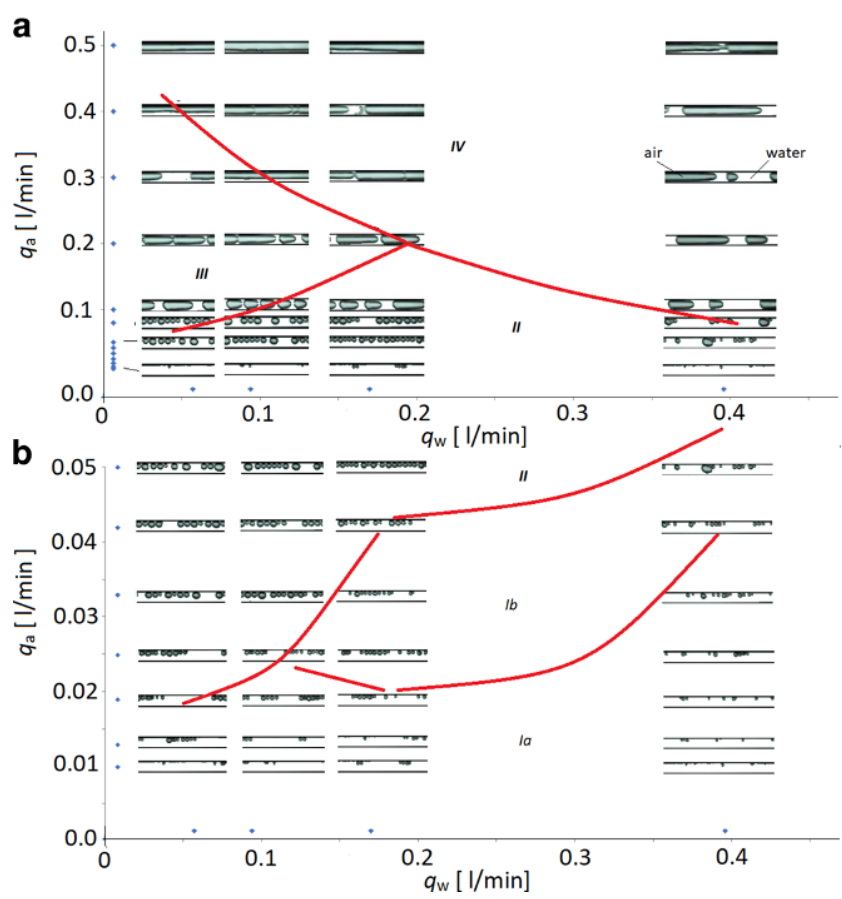

Fig. 6 Location of maxima of $\Delta h$ vs. $q_{a}$ and $q_{w} . I a, I b, I I, I I I$, and $I V$ denote various patterns of bubbles flow. Ia flow of separated microbubbles, $I b$ flow of grouped micro-bubbles, $I I$ flow of grouped microand minibubbles, III flow of micro- and mini-bubbles with confined bubbles, $I V$ slug flow and stratified flow. The red curves define the separation of the identified regions. The additional camera snapshots confirm the identification procedure

video frames were presented. Such points can be treated as the borders between different two phase flow patterns. The following two phase flow patterns were identified: $I$-flow of micro-bubbles, II-flow of grouped micro- and minibubbles, III-flow of micro- and mini-bubbles with confined bubbles, $I V$-slug flow and stratified flow.

Presumably, the bubble merging is signalled by the transition phenomenon between the possible topological forms of the bubbles air and water flow rates. Consequently, the maxima of $\Delta h$ separates different characteristic shapes/ lengths of the bubbles. On the basis of the above analysis we propose the phase diagram presented in Fig. 6 . Here, Fig. 6 shows the selected visual flow images with the transient bubble formations marked in red lines. It should be noted, that we found five different flow patterns. The maxima of functions $\Delta h=h_{\max }-h_{\min }$ vs. $q_{a}$ identify the following two phase flow patterns: $I a$-flow of separated micro-bubbles, $I b$ - flow of grouped micro-bubbles, $I I$ - flow of grouped micro- and minibubbles, $I I I$ - flow of micro- and mini-bubbles with confined bubbles, $I V$-slug flow and stratified flow. 
a

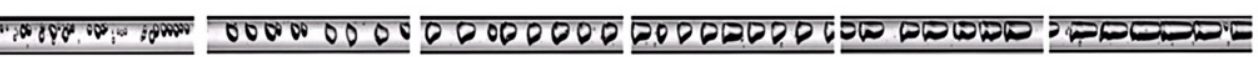
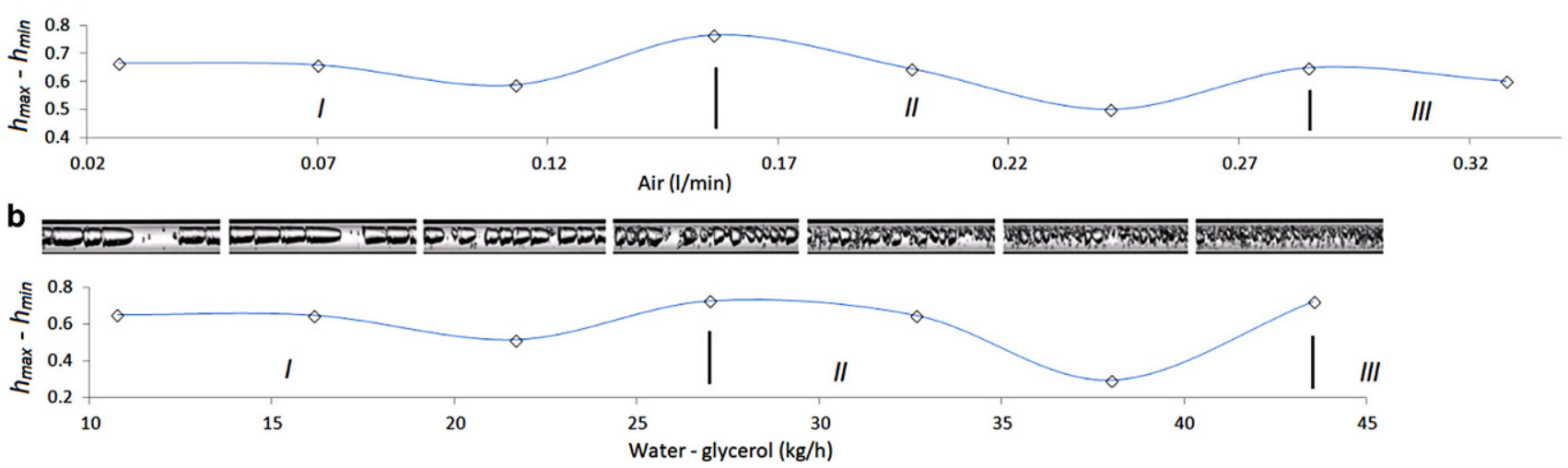

Fig. 7 The air and water mixed with glycerol (solution's concentration: $45 \%$ ) flow. a Changing of $h_{\max }-h_{\min } \mathrm{vs.} q_{a}$ for $q_{w-g}=16.15 \mathrm{~kg} / \mathrm{h}$. Location of max of $\Delta h$ identify the $q_{a}[1 / \mathrm{min}]$ value for which the flow pattern is changing. Three flow patterns have been identified: $I$ bubbles flow, $I I$ cap bubbles and slug flow, III slug flow. b Changing of $h_{\max }-h_{\min }$ vs. $q_{w-g}$ for $q_{a}=0.285 \mathrm{l} / \mathrm{min}$. Location of max of $\Delta h$ identify the $q_{w-g}[\mathrm{~kg} / \mathrm{h}] \mathrm{value}$ for which the flow pattern is changing. Three flow patterns have been identified: $I$ cap bubbles and slug flow, $I I$ small bubbles flow, $I I I$ dispersed flow

\section{Conclusions}

The method of identification of two-phase flow patterns in minichannels presented in the paper is based on the analysis of the dynamics of pressure drop fluctuations. It has been shown that multifractal analysis of pressure fluctuations allows us to identify the two-phase flow patterns. In our approach the air-water flow system has been described in terms of complexity parameters.

For evaluation of the possibility of use of the proposed method for different liquids and different channel shape the two-phase flow inside a circular glass minichannel (diameter $=3 \mathrm{~mm}$ and length of $60 \mathrm{~mm}$ ) has been analysed. The pressure drop in flow of air and water mixed with glycerol (solution's concentration: $45 \%$ ) has been analysed. Scheme of experimental stand is shown in Fig. 1-in this case element 1 was the glass circular minichannel. In Fig. 7 it has been shown identified flow patterns for different air flow rate (Fig. 7a) and different water-glycerol flow rate (Fig. 7b), In case shown in Fig. 7a the three flow patterns were identified: $I$-bubbles flow, $I I-$ cap bubbles and slug flow, III-slug flow. In case shown in Fig. $7 \mathrm{~b}$ also three flow patterns were identified: $I$-cap bubbles and slug flow, II - small bubbles flow, III-dispersed flow. Obtained result confirms the proposed in the paper method of pressure drop fluctuation analysis can be used for two phase flow patterns identification.

The results of the analysis create a 2D map describing the dynamics of changes of pressure fluctuations in time. The map shows the nature of recorded signal dynamics as a function of the water and air flow rates. Based on the analysis of photographs taken using the high speed camera, the areas of appearance of particular flow patterns have been shown on the map. The borders obtained in this way define the areas of the occurrence of flow patterns and simultaneously characterize the dynamics during the changing flow patterns The results confirm that this type of analysis can be treated as an alternative way to identify two-phase flow patterns in the minichannels. The final verification of the proposed method requires a large number of measurements and analyzes of pressure drop fluctuations for different types of two-phase flows.

Funding Open access funding provided by Lublin University of Technology.

Conflict of interest R. Mosdorf, G. Litak, G. Górski, J. Augustyniak and I. Zaborowska declare that they have no competing interests.

Open Access This article is licensed under a Creative Commons Attribution 4.0 International License, which permits use, sharing, adaptation, distribution and reproduction in any medium or format, as long as you give appropriate credit to the original author(s) and the source, provide a link to the Creative Commons licence, and indicate if changes were made. The images or other third party material in this article are included in the article's Creative Commons licence, unless indicated otherwise in a credit line to the material. If material is not included in the article's Creative Commons licence and your intended use is not permitted by statutory regulation or exceeds the permitted use, you will need to obtain permission directly from the copyright holder. To view a copy of this licence, visit http://creativecommons.org/licenses/by/4. $0 /$.

\section{References}

1. Zhao L, Rezkallah KS (1993) Gas-liquid flow patterns at microgravity conditions. Int J Multiph Flow 19:751-763. https://doi.org/ 10.1016/0301-9322(93)90041-R

2. Wongwises S, Pipathattakul M (2006) Flow pattern, pressure drop and void fraction of two-phase gas-liquid flow in an inclined narrow annular channel. Exp Therm Fluid Sci 30:345-354. https://doi. org/10.1016/j.expthermflusci.2005.08.002 
3. Chen L, Tian YS, Karayiannis TG (2006) The effect of tube diameter on vertical two-phase flow regimes in small tubes. Int J Heat Mass Transf 49:4220-4230. https://doi.org/10.1016/j. ijheatmasstransfer.2006.03.025

4. Zong YB, Jin ND, Wang ZY, Gao ZK, Wang C (2010) Nonlinear dynamic analysis of large diameter inclined oil-water two phase flow pattern. Int J Multiphase Flow 36:166-183. https://doi.org/10. 1016/j.ijmultiphaseflow.2009.11.006

5. Triplett KA, Ghiaasiaan SM, Abdel-Khalik SI, Sadowski DL (1999) Gas-liquid two-phase flow in micro-chanels part I: twophase flow patterns. Int J Multiphase Flow 25:377-394. https://doi. org/10.1016/S0301-9322(98)00054-8

6. Serizawa A, Feng Z, Kawara Z (2002) Two-phase flow in microchannels. Exp Therm Fluid Sci 26:703-714. https://doi.org/10. 1016/S0894-1777(02)00175-9

7. Wang SF, Mosdorf R, Shoji M (2003) Nonlinear analysis on fluctuation feature of two-phase flow through a T-junction. Int J Heat Mass Transf 46:1519-1528. https://doi.org/10.1016/S00179310(02)00455-6

8. Jin ND, Nie XB, Ren YY, Liu XB (2003) Characterization of oil/water two-phase flow patterns based on nonlinear time series analysis. Flow Meas Instrum 14:169-175. https://doi.org/10.1016/ S0955-5986(03)00022-0

9. Górski G, Litak G, Mosdorf R, Rysak A (2015) Two phase flow bifurcation due to turbulence: transition from slugs to bubbles. Eur Phys J B. https://doi.org/10.1016/S0955-5986(03)00022-0

10. Górski G, Litak G, Mosdorf R, Rysak A (2015) Self-aggregation phenomenon and stable flow conditions in a two-phase flow through a minichanel. Z Naturforsch A 70(10):843-849. https://doi.org/10. 1515/zna-2015-0264

11. Gorski G, Litak G, Mosdorf R, Rysak A (2016) Dynamics of a twophase flow through a minichannel: transition from churn to slug flow. Eur Phys J Plus. https://doi.org/10.1140/epjp/i2016-16111-x

12. Fan C-L, Jin N-D, Chen X-T, Gao Z-K (2013) Multi-scale permutation entropy: a complexity measure for discriminating twophase flow dynamics. Chin Phys Lett 30(9):90501. https://doi.org/ 10.1088/0256-307X/30/9/090501

13. Fan C, Li H, Ren X (2015) The order recurrence quantification analysis of the characteristics of two-phase flow pattern based on multiscale decomposition. Trans Inst Meas Control 37(6):793-804. https://doi.org/10.1177/0142331214546881

14. Lian E, Ren Y, Han Y, Liu W, Jin N, Zhao J (2016) Multi-scale morphological analysis of conductance signals in vertical upward gas-liquid two-phase flow. Z Naturforsch A 71(11):1031-1052. https://doi.org/10.1515/zna-2016-0235

15. Faszczewski M, Gorski G, Mosdorf R (2012) Applying recurrence plots to identify borders between two-phase flow patterns in vertical circular mini channel. Acta Mech Autom 6(1):31-36

16. Litak G, Górski G, Mosdorf R, Rysak A (2017) Study of dynamics of two-phase flow through a minichannel by means of recurrences. Mech Syst Signal Process 89:48-57. https://doi.org/10.1016/j. ymssp.2016.08.037
17. Gorski G, Litak G, Mosdorf R, Rysak A (2017) Gas bubbles and slugs crossover in air-water two-phase flow by multifractals. Z Naturforsch A 72:535-539. https://doi.org/10.1515/zna-20170031

18. Mosdorf R, Górski G (2016) Identification of two-phase flow patterns in minichannel based on RQA and PCA analysis. Int J Heat Mass Transf 96:64-74. https://doi.org/10.1016/j.ijheatmasstransfer. 2016.01.015

19. Benouioua D, Candusso D, Harel F, Oukhellou L (2014) Fuel cell diagnosis method based on multifractal analysis of stack voltage signal. Int J Hydrogen Energy 39(5):2236-2245. https://doi.org/10. 1016/j.ijhydene.2013.11.066

20. Zuo R, Wang J (2016) Fractal/multifractal modeling of geochemical data: a review. J Geochem Explor 164:33-41. https://doi.org/10. 1016/j.gexplo.2015.04.010

21. Telesca L, Lapenna V (2006) Measuring multifractality in seismic sequences. Tectonophysics 423:115-123. https://doi.org/10.1016/j. tecto.2006.03.023

22. Nichols JM, Trickey ST, Seaver M, Moniz L (2007) Use of fiberoptic strain sensors and holder exponents for detecting and localizing damage in an experimental plate structure. J Intell Mater Syst Struct 18:51-67. https://doi.org/10.1177/1045389X06064354

23. Geca M, Litak G (2017) Mean effective pressure oscillations in an IC-SI engine after the addition of hydrogen-rich gas. Measurement 108:18-25. https://doi.org/10.1016/j.measurement.2017.05.025

24. Curto-Risso PL, Medina A, Calvo Hernández A, Guzmán-Vargas L, Angulo-Brown F (2010) Monofractal and multifractal analysis of simulated heat release fluctuations in a spark ignition heat engine. Physica A 389:5662-5670. https://doi.org/10.1016/j.physa.2010. 08.024

25. Zhu L, Jin N-D, Gao ZK, Zong Y-B (2014) Multifractal analysis of inclined oil-water countercurrent flow. Pet Sci 11:111-121. https:// doi.org/10.1007/s12182-014-0322-9

26. Rasthofer U, Wall WA, Gravemeier V (2018) An extended algebraic variational multiscale-multigrid-multifractal method (XAVM4) for large-eddy simulation of turbulent two-phase flow. J Comput Phys 359:1-19. https://doi.org/10.1016/j.jcp.2018.01.013

27. Muzy JF, Bacry E, Arneodo A (1993) Multifractal formalism for fractal signals: the structure-function approach versus the wavelettransform modulus-maxima method. Phys Rev E Stat Phys Plasmas Fluids Relat Interdiscip Topics 47:875-884. https://doi.org/10. 1103/PhysRevE.47.875

28. Goldberger AL, Amaral N, Glass L, Hausdorff JM, Ivanov PC, Mark RG, Mietus JE, Moody GB, Peng C-K, Stanley HE (2000) PhysioBank, physioToolkit, and physioNet components of a new research resource for complex physiologic signals. Circulation 101:215-220

29. Doukhan P, Oppenheim G, Taqqu MS (eds) (2001) Long range dependence: theory and applications. Birkhauser, Cambridge, p 625 